\begin{tabular}{ll|l}
\cline { 2 - 3 } & \multicolumn{2}{l}{ Intervent Neurol 2013;2:118-122 } \\
\cline { 2 - 4 } & $\begin{array}{l}\text { DOI: 10.1159/000357167 2014 S. Karger AG, Basel } \\
\text { Published online: March 21, 2014 }\end{array}$ & $\begin{array}{l}\text { 1664-9737/14/0023-0118 } \$ 39.50 / 0 \\
\text { www.karger.com/ine }\end{array}$ \\
\hline
\end{tabular}

\title{
Review
}

\section{Carotid Baroreceptor Stimulation: A Potential Solution for Resistant Hypertension}

\author{
Jun Zhang ${ }^{\mathrm{a}}$ Shuyu Zhou ${ }^{\mathrm{a}}$ Gelin Xu $\mathrm{Xu}^{\mathrm{a}} \mathrm{b}$ \\ a Department of Neurology, Jinling Hospital, Nanjing University School of Medicine, and \\ ${ }^{b}$ Department of Neurology, Jinling Hospital, Southern Medical University, Nanjing, China
}

\section{Key Words}

Carotid sinus · Baroreceptor · Electrical stimulation · Resistant hypertension

\begin{abstract}
Resistant hypertension indicates that the blood pressure cannot reach the target value despite standard drug treatment, which harbors an increased risk for cardiovascular diseases. The role of the carotid sinus in regulating blood pressure has long been observed; thereby, the idea that treating resistant hypertension by stimulating carotid baroreceptors emerged. Nevertheless, this idea has been abandoned for years due to technical limitations. Recently, with the evolutions in implantable electrical devices, expectations for treating resistant hypertension with baroreceptor stimulation have increased. Positive results from several multicenter clinical trials further captured the researchers' enthusiasm for more effective baroreceptor-stimulating devices. This study reviews the recent progress in baroreceptor stimulation as a treatment alternative for resistant hypertension.

(C) 2014 S. Karger AG, Basel
\end{abstract}

\section{Resistant Hypertension and Carotid Baroreceptor Stimulation}

Resistant hypertension is defined as blood pressure remaining above the target value in spite of the concurrent use of three antihypertensive agents of different classes. Ideally, one of the three agents should be a diuretic and all agents should be prescribed at optimal dose amounts $[1,2]$. While the exact prevalence of resistant hypertension is unknown, clinical trials suggested that it is not rare, involving about $20-30 \%$ of all study participants [3]. 
A carotid sinus is a dilated area located in the bifurcation of the carotid artery. It contains numerous baroreceptors, which are stretch-sensitive mechanoreceptors and innervated by the carotid sinus nerve. Carotid sinus baroreceptors are sensitive baroreceptors that can sense the intra-arterial blood pressure change and regulate the sympathetic tone towards the opposite direction (as a negative feedback) [4]. When blood pressure is elevated, carotid baroreceptors are activated to send signals to the brain stem nuclei in which inhibitory signals are delivered to attenuate the sympathetic tone and subsequently the blood pressure after a complex signal reception and conversion process [5].

\section{The History of Carotid Baroreceptor Stimulation}

The idea of stimulating carotid baroreceptors as an approach to lower blood pressure is not new [6]. More than a century ago, Cooper [7] uncovered the roles of the baroreceptor system in regulating blood pressure. It was demonstrated that in animals, the blood pressure decreased when the carotid sinus nerve was electrically stimulated, while it increased if the nerve was transected. In 1965, the pioneering work by Bilgutay and Lillehei [8] utilized a compact implantable device with two electrodes attached directly to the carotid sinus of seven hypertensive dogs. The results indicated that bilateral electrical stimulation of the baroreceptors for $2 \mathrm{~h}$ caused a drop in blood pressure, with a reduction in systolic blood pressure (SBP) ranging from 35 to $100 \mathrm{~mm} \mathrm{Hg}$ and from 25 to $75 \mathrm{~mm} \mathrm{Hg}$ in diastolic blood pressure [8]. One year later, they employed this technique in 2 patients: 1 had a blood pressure reduction from $250 / 160$ to $130 / 90 \mathrm{~mm} \mathrm{Hg}$ and the other from $280 / 160$ to $140 / 100 \mathrm{~mm} \mathrm{Hg}$ [9]. Clinical studies demonstrated that the mechanism of resetting and the insensitivity of the baroreceptor system contributed to the elevated blood pressure in hypertensive patients [10, 11]. These data indicated that the primary function of the baroreceptor system was to balance the sympathetic and vagal tone, thereby regulating blood pressure. Unfortunately, at that time, the baroreflex was regarded as a short-term regulation system with temporal effects. This recognition, together with adverse effects, discouraged further investigation of carotid baroreceptor stimulation as a potential treatment for hypertension.

\section{Recent Technical Progress in Carotid Baroreceptor Stimulation}

Recently, with the accumulation of knowledge on baroreflex and technical progress, treating resistant hypertension with carotid baroreceptor stimulation has emerged and been popularized. Results from recent studies have suggested that the baroreflex also exerts a long-time control on the sympathetic output and participates in the balance of body fluid volume regulated by kidney, and is thus involved in the long-term regulation of blood pressure $[12,13]$. In 2004, Lohmeier et al. [14] showed that prolonged bilateral stimulation of carotid baroreceptors in conscious dogs could reduce blood pressure and heart rate significantly for 7 days. Thereafter, they confirmed these results in both normotensive and hypertensive dogs $[15,16]$. The first clinical study evaluating the efficacy and safety of carotid baroreceptor stimulation for long-term treatment of hypertension was performed in 2004. A hypertensive patient with end-organ damage underwent carotid baroreceptor stimulation. Blood pressure decreased by 38/8 mm Hg and remained well for 1 month [17].

Several implantable devices for carotid baroreceptor stimulation have been developed, which facilitates research in this field [18]. The Rheos Baroreflex Hypertension Therapy System (CVRx, Minneapolis, Minn., USA) consists of an implantable pulse generator, two electrode leads attached to the carotid sinus and an external programming system. The pulse 
generator delivers activation energy (voltage range 1-7.5 V) through electrode leads to stimulate the carotid sinus, and then the triggered baroreceptors send signals to the brain, which are interpreted as a rise in blood pressure. The brain initiates the body's own control mechanisms to counteract this perceived rise in blood pressure by delivering signals to other parts of the body to reduce blood pressure. In their study, Heusser et al. [19] have shown that the depressor response was achieved through sympathetic inhibition, together with a decrease of the heart rate. However, there were no negative effects on the physiological regulation of the baroreflex. Moreover, there was a correlation between depressor response and the reduction of muscle sympathetic nerve activity. After implantation, the device should not be switched on until the patients recover for 1 month. Then, they should undergo a dose-response test and parameter settings (typically $100 \mathrm{~Hz}$ of continuous bilateral stimulation, $<7 \mathrm{~V}$ ) to obtain an optimal antihypertensive efficacy.

Several influential studies have evaluated the efficacy and safety of carotid baroreceptor stimulation in the short-time and long-time control of blood pressure. In a phase II feasibility trial [20], 10 patients with resistant hypertension (SBP $\geq 160 \mathrm{~mm} \mathrm{Hg}$ ) were enrolled and successfully underwent bilateral implantation of the Rheos system. As the voltage increased, the mean SBP decreased from 170 to $133 \mathrm{~mm} \mathrm{Hg}$ in an intraoperative test and from 180 to $139 \mathrm{~mm} \mathrm{Hg}$ before hospital discharge. Moreover, it revealed a linear relationship between voltage value and hemodynamic response $(r=0.88)$, with the maximal response observed at around $4.8 \mathrm{~V}$. There were no unanticipated serious adverse events (SAEs) throughout the trial process. The Rheos system has proven to be safe and effective in the treatment of resistant hypertension.

The DEBuT-HT (Device Based Therapy in Hypertension Trial) was a multicenter, prospective, nonrandomized feasibility study [21]. The study aimed to evaluate the safety and efficacy of the Rheos system over 3 months or longer in patients with resistant hypertension. The trial enrolled 45 patients with a blood pressure of $\geq 160 / 90 \mathrm{~mm} \mathrm{Hg}$. After device implantation, 37 patients were evaluated in the first 3 months. Compared to the baseline mean blood pressure (179/105 $\mathrm{mm} \mathrm{Hg})$, there was a mean reduction of 21/12 mm Hg. During the 1-year and 2-year follow-ups, the mean blood pressure was reduced by 30/20 and 33/22 $\mathrm{mm} \mathrm{Hg}$, respectively. In terms of safety, 7 subjects experienced procedure-related SAEs, and 1 subject experienced device-related SAEs. Most SAEs were related to the individual risks and comorbidities. None of the patients suffered carotid artery stenosis during the follow-up period. During the trial, a substudy of voltage-dependent blood pressure response was conducted at the same time. The voltage response test was performed at 1, 4, and 13 months after implantation. By comparing the index of the baroreflex sensitivity, there were no significant differences between 1, 4, and 13 months. This indicated that the baroreflex function was preserved 1 year after the stimulation, and there was no response adaption or nerve fatigue [22].

The Rheos Pivotal Trial was a prospective, double-blind, randomized, multicenter, placebo-controlled phase III clinical trial to evaluate the efficacy and safety of the Rheos device in patients with resistant hypertension [23]. A total of 265 subjects implanted with the device were randomized (2:1) into two groups. Group A ( $n=181)$ initiated the therapy immediately (the device was activated 1 month after implantation) and group $B(n=84)$ received the therapy 6 months later (the device was activated 7 months after implantation). The trial was designed to demonstrate five primary end points during 12 months of follow-up. The results indicated that the trial did not reach two of the five end points in procedure safety and short-time efficacy. Procedure safety was evaluated by the incidence of adverse events related to the implantation procedure itself within the first 30 days. It showed an event-free rate of $74.8 \%$, which was less than the prespecified target value of $82 \%$. The acute efficacy end point was judged by measuring the proportion of subjects in the two groups that obtained a drop of SBP by at least $10 \mathrm{~mm} \mathrm{Hg}$ within the first 6 months. The results indicated that $54 \%$ of 
subjects in group A and $46 \%$ in group B reached the level. With a superiority margin of $20 \%$ that was set for this end point, the target was not reached either. Apart from these, the other three end points were successfully reached in this study, including 12-month efficacy, carotid baroreceptor stimulation safety and device safety. A secondary analysis indicated that $42 \%$ of patients in group A achieved the target blood pressure (SBP $\leq 140 \mathrm{~mm} \mathrm{Hg}$ ) at the 6-month evaluation, while only $22 \%$ of patients in group B achieved this level $(p=0.005)$. There were no significant differences between the two groups at the 12-month evaluation. This study showed that $63 \%$ of subjects reached the target SBP of $\leq 140 \mathrm{~mm} \mathrm{Hg}$, and $81 \%$ of subjects achieved a minimum of $10 \mathrm{~mm} \mathrm{Hg}$ reduction after implantation. Thereafter, the subjects consented to participate in a longer, nonrandomized follow-up lasting from 22 to 53 months. During the follow-up, the mean blood pressure was reduced by $35 / 16 \mathrm{~mm} \mathrm{Hg}$, and $55 \%$ of subjects achieved the target blood pressure. The results have revealed an even longer control of blood pressure through carotid baroreceptor stimulation [24].

To facilitate the operational process of the device implantation, the Barostim $n e o^{\mathrm{TM}}$ system, a second-generation system for carotid baroreceptor stimulation has been developed [25]. Compared to the previously developed Rheos system, the Barostim neo system consists of one pulse generator, one lead electrode directly sutured to the unilateral carotid sinus and a laptop computer-based programming system. The carotid sinus electrode serves as cathode ( $6 \mathrm{~mm}$ in diameter), while the pulse generator acts as anode. In an open-label, nonrandomized study of 30 resistant hypertensive patients implanted with the Barostim neo system, blood pressure averagely decreased by $26 / 12 \mathrm{~mm} \mathrm{Hg}$ during the 6-month follow-up. The results were comparable to those in the DEBuT-HT [21] and Rheos Pivotal Trial using the Rheos system [23]. The percentage of patients achieving an SBP of $<140 \mathrm{~mm} \mathrm{Hg}$ reached $43 \%$, consistent with that in the Rheos Pivotal Trial (42\%). Therefore, the second-generation system can significantly lower blood pressure, with similar efficacy compared to the Rheos system. In terms of safety, up to $90 \%$ of patients were free from system- or procedure-related adverse events within the first 30 days after implantation. A similar result (88\%) was achieved in a study on short-time cardiac pacemaker implantation [26]. During long-time observation (>180 months), $97 \%$ of the patients remained event-free. Furthermore, implantation process time decreased from $198 \mathrm{~min}$ with the Rheos system to $107 \mathrm{~min}$ with the second-generation system due to the unilateral exposure of the carotid sinus. The second-generation, minimally invasive system has preliminarily demonstrated its safety and efficacy in the treatment of resistant hypertension, and a large, randomized controlled trial is currently being planned in full swing in North America for further study [27].

\section{Limitations and Future Directions}

Carotid baroreceptor stimulation has been demonstrated to have great potential for treating resistant hypertension. However, this therapy is not suitable for all types of hypertension (e.g. angiotensin II-induced hypertension). In some previous trials, hypertensive patients were treated simultaneously by carotid baroreceptor stimulation and antihypertensive drugs. A case report showed that blood pressure increased when stimulating the carotid baroreceptor alone. Therefore, at present, it is still not possible to free patients completely from medication treatment by the carotid baroreceptor stimulation. All present devices depend on an external computer-controlled system rather than an in vivo closed-loop feedback system. Thus, further studies are warranted to probe the mechanism of blood pressure regulation and to develop self-regulating devices with a closed-loop feedback. 


\begin{tabular}{l|l}
\hline Intervent Neurol 2013;2:118-122 \\
\hline DOI: $\underline{10.1159 / 000357167}$ & $\begin{array}{l}\text { C 2014 S. Karger AG, Basel } \\
\text { www.karger.com/ine }\end{array}$ \\
\hline
\end{tabular}

Zhang et al.: Carotid Baroreceptor Stimulation: A Potential Solution for Resistant Hypertension

\section{References}

1 Daugherty SL, Powers JD, Magid DJ, Tavel HM, Masoudi FA, Margolis KL, et al: Incidence and prognosis of resistant hypertension in hypertensive patients. Circulation 2012;125:1635-1642.

- 2 Calhoun DA, Jones D, Textor S, Goff DC, Murphy TP, Toto RD, et al: Resistant hypertension: diagnosis, evaluation, and treatment a scientific statement from the American Heart Association Professional Education Committee of the Council for High Blood Pressure Research. Hypertension 2008;51:1403-1419.

3 Acelajado MC, Calhoun DA: Resistant hypertension, secondary hypertension, and hypertensive crises: diagnostic evaluation and treatment. Cardiol Clin 2010;28:639-654.

4 Thrasher TN: Unloading arterial baroreceptors causes neurogenic hypertension. Am J Physiol Regul Integr Comp Physiol 2002;282:R1044-R1053.

5 Papademetriou V, Doumas M, Faselis C, Tsioufis C, Douma S, Gkaliagkousi E, et al: Carotid baroreceptor stimulation for the treatment of resistant hypertension. Int J Hypertens 2011;2011:964394.

- 6 Warner HR: The frequency-dependent nature of blood pressure regulation by the carotid sinus studied with an electric analog. Circ Res 1958;6:35-40.

7 Cooper A: Guy's hospital report; in Heymans C, Neil E (eds): Reflexogenic Areas of the Cardiovascular System. London, J\&A Churchill, 1858, p 457.

- 8 Bilgutay AM, Lillehei CW: Treatment of hypertension with an implantable electronic device. JAMA 1965;191: 649-653.

9 Bilgutay AM, Lillehei CW: Surgical treatment of hypertension with reference to baropacing. Am J Cardiol 1966; 17:663-667.

10 McCubbin J, Green J, Page IH: Baroceptor function in chronic renal hypertension. Circ Res 1956;4:205-210.

11 Bristow JD, Honour AJ, Pickering GW, Sleight P, Smyth HS: Diminished baroreflex sensitivity in high blood pressure. Circulation 1969;39:48-54.

12 Thrasher TN: Baroreceptors and the long-term control of blood pressure. Exp Physiol 2004;89:331-335.

13 Kougias P, Weakley SM, Yao Q, Lin PH, Chen C: Arterial baroreceptors in the management of systemic hypertension. Med Sci Monit 2010;16:RA1.

14 Lohmeier TE, Irwin ED, Rossing MA, Serdar DJ, Kieval RS: Prolonged activation of the baroreflex produces sustained hypotension. Hypertension 2004;43:306-311.

15 Barrett AM, Irwin ED: Prolonged activation of the baroreflex: a viable approach for the treatment of hypertension? Curr Hypertens Rep 2005;7:193-198.

16 Lohmeier TE, Dwyer TM, Hildebrandt DA, Irwin ED, Rossing MA, Serdar DJ, et al: Influence of prolonged baroreflex activation on arterial pressure in angiotensin hypertension. Hypertension 2005;46:1194-1200.

17 Mohaupt M, Cain C, Frey F: Chronic electrical activation of the carotid sinus baroreflex by implanted electrodes for blood pressure reduction in man: first experience in a hypertensive patient. Kidney Blood Press Res 2004; 27:299.

18 Tordoir J, Scheffers I, Schmidli J, Savolainen H, Liebeskind U, Hansky B, et al: An implantable carotid sinus baroreflex activating system: surgical technique and short-term outcome from a multi-center feasibility trial for the treatment of resistant hypertension. Eur J Vasc Endovasc Surg 2007;33:414-421.

19 Heusser K, Tank J, Engeli S, Diedrich A, Menne J, Eckert S, et al: Carotid baroreceptor stimulation, sympathetic activity, baroreflex function, and blood pressure in hypertensive patients. Hypertension 2010;55:619-626.

20 Illig KA, Levy M, Sanchez L, Trachiotis GD, Shanley C, Irwin E, et al: An implantable carotid sinus stimulator for drug-resistant hypertension: surgical technique and short-term outcome from the multicenter phase II Rheos feasibility trial. J Vasc Surg 2006;44:1213-1218.

-21 Scheffers IJ, Kroon AA, Schmidli J, Jordan J, Tordoir JJ, Mohaupt MG, et al: Novel baroreflex activation therapy in resistant hypertension: results of a European multi-center feasibility study. J Am Coll Cardiol 2010;56: 1254-1258.

22 Alnima T, Scheffers I, De Leeuw PW, Winkens B, Jongen-Vancraybex H, Tordoir JH, et al: Sustained acute voltage-dependent blood pressure decrease with prolonged carotid baroreflex activation in therapy-resistant hypertension. J Hypertens 2012;30:1665-1670.

23 Bisognano JD, Bakris G, Nadim MK, Sanchez L, Kroon AA, Schafer J, et al: Baroreflex activation therapy lowers blood pressure in patients with resistant hypertension: results from the double-blind, randomized, placebocontrolled rheos pivotal trial. J Am Coll Cardiol 2011;58:765-773.

-24 Bakris GL, Nadim MK, Haller H, Lovett EG, Schafer JE, Bisognano JD: Baroreflex activation therapy provides durable benefit in patients with resistant hypertension: results of long-term follow-up in the Rheos Pivotal Trial. J Am Soc Hypertens 2012;6:152-158.

25 Hoppe UC, Brandt M-C, Wachter R, Beige J, Rump LC, Kroon AA, et al: Minimally invasive system for baroreflex activation therapy chronically lowers blood pressure with pacemaker-like safety profile: results from the Barostim neo trial. J Am Soc Hypertens 2012;6:270-276.

-26 Udo EO, Zuithoff N, van Hemel NM, de Cock CC, Hendriks T, Doevendans PA, et al: Incidence and predictors of short- and long-term complications in pacemaker therapy: the FOLLOWPACE study. Heart Rhythm 2012;9: 728-735.

27 Wustmann K, Kucera JP, Scheffers I, Mohaupt M, Kroon AA, de Leeuw PW, et al: Effects of chronic baroreceptor stimulation on the autonomic cardiovascular regulation in patients with drug-resistant arterial hypertension. Hypertension 2009;54:530-536. 